\title{
Identity politics: \\ A view from the South
}

[ B O O K R E V I E W ]

Ispas, Alexa (2013) Psychology and politics:

\section{A social identity perspective.}

London \& New York: Psychology Press.

ISBN 978-0-415-67770-7 hbk. Pages xi +129.

\section{Shose Kessi}

Department of Psychology

University of Cape Town

Rondebosch,

Cape Town

\section{Psychology and politics: A social identity perspective is} a commendable effort and valuable resource for anyone interested in social psychology, particularly the role of social identity in understanding human behaviour.

The book provides a detailed and informative presentation of the concepts and methods underlying the social identity perspective in social psychology. It demonstrates the value of the social identity perspective as one of the most important developments in social psychology. The author suggests four pertinent areas of political behaviour for which a social identity perspective can be useful: social influence, crowd behaviour, political leadership and authoritarian regimes.

It is written in a language that is accessible and presented in an attractive format for both students and teachers. Each chapter is preceded by learning objectives and ends with a summary of key points. Furthermore, the theoretical concepts are well illustrated through comprehensive descriptions of experimental methods and accompanied by examples relating to contemporary political concerns. All of these elements contribute to a compelling read.

The author starts by locating the text as a departure from the individualistic focus of much mainstream social 
psychology towards a more social, social psychology. Beginning with an account of Henri Tajfel's life as a Polish Jew during the Holocaust, the author highlights the importance of the life experiences of researchers and how these often underlie the political motivation of academic work. It is also a pertinent starting point as it evokes a central and ongoing tension in social psychology, the individual-social interface. By focusing on the individual, much social psychological work has fallen short of understanding the dynamics of sociopolitical life and has been criticized for contributing to apolitical explanations to social problems, such as inequality and violence.

The social identity perspective provided in this book attempts to re-instate the value of social psychology as a discipline that can work to address the concerns of marginalized groups, resolve conflict, and promote positive change in society. In line with the view expressed by social psychologist Michael Billig (2002) who has referred to social identity as a theory of "group freedom", the book provides interesting insights and recommendations for anyone concerned with the role of collective action for social change. Indeed, it is acknowledged throughout the text that social and political change happens through the collective action of groups - and that it is the social identity of a group, developed through group life, that provides the engine for change.

Through a thoughtful analysis of group identity, the author challenges many accepted and often conservative ideas about political behaviour that have emerged from traditional social psychology theories. A re-examination of conformity studies, group polarization, minority influence and groupthink offers a critical perspective on how individuals negotiate their private and public attitudes and beliefs in relation to their group membership. This in turn provides valuable information on the type of political messages that may facilitate social influence and lead to change.

Mainstream accounts of crowd behaviour as irrational are also put into question by highlighting the power relations between groups in particular contexts, where authorities are also responsible for provoking violence. Crowd behaviour is further explained through the extent to which group norms have been established and correspond to the social identity of the group. This offers a broader and more critical framework with which to analyze the causes of crowd violence and differentiate situations in which violence may erupt, possible ways to prevent it and/or mitigate its impact, and apportion responsibility more objectively.

The critique of leadership theories revolves around the dynamic nature of social identities. Rather than attributing a set of fixed leadership qualities to an individual, the more social approach proposed here emphasizes the shared social identity between leaders and other group members - and the extent to which the leader's identity must

PINS [Psychology in Society] 48 • 2015|102 
be prototypical to the group identity in any particular environment, and therefore often subject to change.

Finally, a critique of Milgram's obedience studies and the Stanford prison experiment reveal the need for a more complex analysis of authoritarian forms of political behaviour that does not assume that people are naturally prone to evil. Instead, it is argued that people make decisions depending on the extent that they share a social identity with the authoritarian figure and the limitations of the context in which they find themselves. This section of the book provides a helpful presentation of what is perhaps one of the most interesting and under-theorized aspects of Tajfel's social identity theory - also the most socially-oriented aspect of the theory - which is the investigation of the conditions in which people choose to participate in social change through a variety of proposed identity strategies.

A very important message of the book is that political behaviour is mediated by the social context - specifically, political behaviour is associated with and dependent on the social identities of groups. Nevertheless, this aspect of the book is also the one area that could be developed further.

A critique of the individualism of social psychology necessarily involves a critique of the methodological approaches that underlie much of its work. The focus on experimental methods has been widely criticized by social-oriented theorists. Firstly, the majority of the experimental studies described in the book rely on white, heterosexual, able-bodied men as the norm by which behaviour is measured. Secondly, the ethics of the Milgram and Zimbardo studies should also be raised, particularly the fact that participants were prompted to inflict harm onto others. The assumption made is that new knowledge will be produced as the outcome of the experiment when in fact knowledge is produced through the experiment itself - in other words, experiments reveal as much about the behaviour of researchers as they do about the behaviour of participants. Furthermore, caution should be exercised when extrapolating the results of experimental studies conducted in laboratories and under specific conditions to real life circumstances (Moghaddam \& Taylor, 1994). Given the space afforded to explaining the experiments and the emphasis on the social, the book would have benefitted from a more critical perspective on methodological principles.

A second area that would enhance the socially-oriented nature of the book is further attention to the majority versus minority discourse that is prevalent in social psychological studies. This discourse is problematic in many contemporary contexts where minorities have political power. It presupposes a numerical disadvantage when this is often not the case (e.g. women), and importantly, it ignores the power processes between so-called 
minority and majority perspectives, which appear as simply perspectives that contradict each other. A discourse of "marginalized" or "oppressed" versus "dominant" groups is more appropriate to account for the power relations between groups and how the socalled 'minority' view is actively discredited by the so-called "majority" view.

This brings me to the final and perhaps most important question about the social context that impacts on political behaviour. Notably absent is a mention of ideology - how capitalism, racism, and patriarchy, for example, might impact on social identities and the possibilities for collective action. In contemporary societies, participating in social change is complex, as the identities of many groups are not seen as legitimate in formal political discourse. In many democracies, marginalized ethnicities, LGBT people, and sex worker groups, for example, are excluded from dominant beliefs and institutional practices. This situation highlights the contradictions that exist between the individual rights and freedoms of modernity and the daily experiences of marginalized groups. Hence, violence and inequalities are not only the prerogative of authoritarian regimes. Political power is influenced by ideological constructions that often conceal relations of power and operate in ways that maintain and justify violence and inequality. A concrete example of authoritarianism is illustrated through the case of Nazi Germany, but it would be interesting to understand this process in contemporary democratic regimes as well. A key criticism of social identity theory is that it does not explain how social hierarchies come to be established or how one group comes to dominate or oppress another (Moghaddam \& Taylor, 1994). This book seemed like a perfect opportunity to expand on this aspect of the social identity perspective. One suggestion would be to draw on southern perspectives, such as the notion of intersectionality, a theory of identity emerging from black / African feminisms. Apart from a couple of examples, the book largely focuses on western experiences. A critique of the social identity perspective from the global south is perhaps a book waiting to happen.

\section{References}

Billig, M (2002) Henri Tajfel's "Cognitive aspects of prejudice" and the Psychology of bigotry. British Journal of Psychology, 41(2), 171-188.

Moghaddam, F \& Taylor, D (1994) Theories of intergroup relations: International social psychological perspectives. Westport: Greenwood Publishing. 